\title{
Contribution of inherited factors to rheumatoid arthritis
}

\author{
C M Deighton, J Wentzel, G Cavanagh, D F Roberts, D J Walker
}

\begin{abstract}
A total of 231 sibships of the same sex (186 female, 45 male), in which the proband had classical or definite rheumatoid arthritis (RA) have been selected from rheumatology clinics. Each sibship member was questioned about symptomatic joints, which were then examined. Hospital records, radiographs, and rheumatoid factor measurements allowed each sibling to be classified as having classical, definite, probable, or no RA. Each sibling was typed for HLA-A and B and was classified as sharing two, one, or zero HLA haplotypes with the proband.

Concordance rates for classical and definite RA were three times greater in sibships of women than of men $(9.3 v 3.0 \%)$. Concordance rates in HLA identical sibships were twice those in hemi- and non-identical sibships $(15 \cdot 5,7 \cdot 1$, and $5 \cdot 2 \%$, respectively). Probable RA was more common in male and HLA hemi- and non-identical sibships. These results suggest that female sex and the two inherited HLA haplotypes are important for the presence and expression of RA.

Although environmental factors may be shared more in twins than siblings, a concordance rate of $20.5 \%$ in seropositive HLA identical sibships of the same sex compared with $30 \%$ in monozygotic twins suggests that sex and HLA type account for about two thirds of the inherited risk of RA.
\end{abstract}

Department of

Rheumatology,

Royal Victoria Infirmary,

Newcastle Upon Tyne,

UK

C M Deighton

D J Walker

Department of

Human Genetics,

University of

Newcastle Upon Tyne,

UK

J Wentzel

D F Roberts

Tissue Typing

Laboratory,

Regional Blood

Transfusion Service,

Barrack Road,

Newcastle Upon Tyne,

UK

G Cavanagh

Correspondence to:

Dr C M Deighton,

Department of Rheumatology, Royal Victoria Infirmary, Newcastle Upon Tyne, NE1 4LP, UK.

Accepted for publication 18 March 1991
The cause of rheumatoid arthritis (RA) is not known, but it is generally accepted that a combination of genetic and environmental factors is involved. The evidence for a genetic component comes from a quoted concordance of $30 \%$ for seropositive monozygous twins, ${ }^{1}$ and weak familial clustering of the disease. ${ }^{2}$ However, there are only two inherited factors consistently associated with RA. The first is female sex, with RA affecting three women to one man. ${ }^{1}$ Whether this predisposition is genetic or environmental, or a combination of the two, is not known. The second is the HLA type, particularly DR4, which is present in $70 \%$ of pared with $30 \%$ of controls. ${ }^{3}$ Haplotype sharing studies suggest a linkage between RA and susceptibility gene(s) in the HLA region. ${ }^{4}$ Other reported genetic factors showing associations with RA are weak or inconsistent.

Although female sex and HLA type are clearly important in the aetiology of RA, there are no data which can be used to estimate the relative effects of the presence of these factors, the RA population diagnosed in hospital com- and their influence not only on the presence of RA, but also on disease expression. In addition, although genes associated with HLA haplotypes predispose to the development of RA, it is not known for how much of the genetic predisposition they account. Finally, if sex, HLA type and seropositivity are taken into consideration, it is not known what proportion of the monozygous twin concordance rate can be accounted for.

Data on these issues may provide important clues to the inheritance and disease expression of RA and guide the direction of future research. This study seeks to explore these issues further by establishing RA concordance rates in HLA typed sibships of the same sex classified in hospital clinics.

\section{Methods}

All patients with classical or definite RA determined according to the American Rheumatism Association criteria ${ }^{5}$ seen by two of the authors (CMD and DJW) in the outpatient departments of the Royal Victoria Infirmary and Freeman Hospital in Newcastle Upon Tyne, and Preston Hospital, North Shields, were asked if they had any siblings of the same sex living within $\mathbf{5 0}$ miles of central Newcastle. Those patients answering positively were requested to ask these siblings if they would agree to being visited at home to be assessed for the presence of RA and to have a blood sample taken.

Those sibships in whom the proband and at least one sibling of the same sex agreed to participate were visited by CMD. Each subject was asked their age and to describe any symptoms suggestive of RA. Their hands and any symptomatic joints were examined for swelling, tenderness, and deformity. Members of each sibship were asked if they had attended any hospitals for treatment of rheumatic complaints, and where appropriate their notes and radiographs were obtained. Using the combined data of history, examination, hospital records and radiographs, each subject was classified into one of four categories: classical, definite, probable, or no RA according to the 1958 American Rheumatism Association criteria. ${ }^{5}$

Two of the siblings described a previous self limiting symmetrical polyarthritis, but in these two subjects examination and rheumatoid factor serology were negative, and neither had attended hospital. These subjects were therefore classified as not having RA. Blood was taken from all subjects for serology and HLA-A and B typing. The rheumatoid factor titre was determined by the RA hyaluronic acid test, which detects IgM rheumatoid factor, at the department of 
immunology, Newcastle General Hospital. A total of 153 sibships was HLA typed at the department of human genetics, University of Newcastle Upon Tyne, and 78 at the Regional Blood Transfusion Centre, Newcastle Upon Tyne. Each sibship was typed at only one of the two laboratories. All HLA typing was performed by the microcytotoxicity assay using standard alloantisera. ${ }^{6}$ Fourteen HLA-A and 21 B specificities were tested. Subjects typed at the department of human genetics also had five $\mathrm{Cw}$ specificities tested.

\section{CALCULATION OF CONCORDANCE RATES}

A previous logistic regression analysis had suggested that the best predictor of concordance in a sibship is the size of the sibship, i.e. the larger the sibship, the greater the chance of concordance. ${ }^{7}$ To eliminate this bias, a mean sibship concordance rate was calculated for each sibship: in a sibship where the index subject had only one sibling who was also concordant for $\mathrm{RA}$, the sibship was scored 1.0 ; in a sibship where the index subject had four siblings of whom one was concordant, the sibship was scored $0 \cdot 25$. These scores were totalled and divided by the number of sibships to give a mean concordance rate. A similar approach was taken when calculating the concordance rates in HLA identical, hemi- and non-identical sibships.

Siblings were assumed to be HLA identical if they shared all A and B types, hemi-identical if they shared two or three types, and nonidentical if they shared one or no A and B types. These were taken to represent sharing of two, one, and zero haplotypes, respectively. Where $\mathrm{Cw}$ types were available, this gave further information for haplotype assignment.

\section{Results}

A total of 233 consecutive probands with classical or definite RA who fulfilled the protocol entry criteria agreed to participate. In two sibships it was discovered that the probands only had nonblood related step sisters, and these were therefore withdrawn from the study. This left 231 sibships, of which 223 were completely classified, but in eight sibships in which at least one sibling agreed to participate, ten subjects (two siblings from each of two sibships and one each from a further six) refused to take part. As 381 siblings were approached this represents $2.6 \%$ of the total. Information from the probands suggested that the ten who refused to participate were all probably not affected by RA.

Of the 231 sibships of the same sex, 186 were female and 45 were male. The sibship size ranged from two to six, with a mean (SD) of $2 \cdot 7$ $(1 \cdot 0)$ and a median of $2 \cdot 0$. With respect to the 231 index subjects, 78 siblings of the same sex from 71 sibships were HLA identical, 210 from 161 sibships were hemi-identical, and 83 from 75 sibships were non-identical (sibships with three or more members contained more than one pairing).

Table 1 shows the mean sibship concordance rates for males and females. This shows a higher concordance rate in females than in males, particularly for the presence of classical and definite disease in the siblings of the proband. The table also suggests a tendency for disease expression in female siblings of the proband to be classical or definite RA, whereas male sibships were more likely to contain siblings fulfilling the criteria for probable disease.

Table 2 shows that a comparison between multicase RA sibships, and sibships in which the proband alone had $R A$ revealed that they

Table 1 Comparison of mean sibship rheumatoid arthritis (RA) concordance rates for different American Rheumatism Association criteria disease groups in the siblings of male and female sibships

\begin{tabular}{llll}
\hline $\begin{array}{l}\text { Sex of } \\
\text { sibship } \\
\text { (number of } \\
\text { sibships) }\end{array}$ & $\begin{array}{l}\text { Mean sibship } R A \\
\text { concordance rate } \\
\text { for siblings with } \\
\text { classical and } \\
\text { definite disease* } \\
(\%)\end{array}$ & $\begin{array}{l}\text { Mean sibship } R A \\
\text { concordance rate } \\
\text { for siblings with } \\
\text { probable disease }\end{array}$ & $\begin{array}{l}\text { Total mean sibship } \\
\text { concordance rate* }\end{array}$ \\
$(\%)$ & & \\
\hline Female & $9 \cdot 3$ & $2 \cdot 6$ & $11 \cdot 9$ \\
$(186)$ & $(\mathrm{n}=27)$ & $(\mathrm{n}=3)$ & $(\mathrm{n}=30)$ \\
Male & $3 \cdot 0$ & $4 \cdot 7$ & $7 \cdot 7$ \\
$(45)$ & $(\mathrm{n}=2)$ & $(\mathrm{n}=4)$ & $(\mathrm{n}=6)$ \\
Combined & $8 \cdot 1$ & $3 \cdot 0$ & $11 \cdot 1$ \\
$(231)$ & $(\mathrm{n}=29)$ & $(\mathrm{n}=7)$ & $(\mathrm{n}=36)$ \\
\hline
\end{tabular}

${ }^{*} \mathrm{n}=$ number of sibships with at least one sibling with RA satisfying the specified American Rheumatism Association criteria.

Table 2 Comparison of multicase sibships with sibships in which the proband alone has rheumatoid arthritis (RA), for age of proband, age of siblings, disease duration and sibship size

\begin{tabular}{|c|c|c|c|}
\hline & $\begin{array}{l}\text { Non-multicase } \\
R A \text { sibships }\end{array}$ & $\begin{array}{l}\text { Multicase } \\
R A \text { sibships }\end{array}$ & $\begin{array}{l}\text { Mann-Whitney } \\
U \text { test for } \\
\text { significance } \\
\text { of differences } \\
(p \text { value })\end{array}$ \\
\hline $\begin{array}{l}\text { Number of } \\
\text { probands }\end{array}$ & 195 & 36 & \\
\hline $\begin{array}{l}\text { Mean (SD) age of } \\
\text { proband (years) }\end{array}$ & $56 \cdot 4(12 \cdot 1)$ & $58 \cdot 4(9 \cdot 8)$ & 0.4 \\
\hline $\begin{array}{l}\text { Mean (SD) age of } \\
\text { siblings (years) }\end{array}$ & $55 \cdot 0(12 \cdot 7)$ & $57 \cdot 2(15 \cdot 2)$ & $0 \cdot 1$ \\
\hline $\begin{array}{l}\text { Mean (SD) disease } \\
\text { duration in proband } \\
\text { (years) }\end{array}$ & $12 \cdot 2(11 \cdot 6)$ & $11 \cdot 2(11.9)$ & 0.5 \\
\hline $\begin{array}{l}\text { Mean (SD) sibship } \\
\text { size, including } \\
\text { index case }\end{array}$ & $2.6(0.9)$ & $3.3(1.4)$ & 0.001 \\
\hline
\end{tabular}


Table 3 Comparison of mean sibship classical and definite rheumatoid arthritis $(R A)$ concordance rates (with probable $R A$ in parentheses) in female and male sibships for siblings sharing two, one and zero haplotypes with the proband

\begin{tabular}{|c|c|c|c|}
\hline $\begin{array}{l}\text { Sex of } \\
\text { sibship } \\
\text { (number of } \\
\text { sibships) }\end{array}$ & $\begin{array}{l}\text { Mean } R A \text { sibship } \\
\text { concordance rate } \\
\text { for siblings } H L A \\
\text { identical to } \\
\text { proband (\%) }\end{array}$ & $\begin{array}{l}\text { Mean RA sibship } \\
\text { concordance rate } \\
\text { for siblings HLA } \\
\text { hemi-identical to } \\
\text { proband (\%) }\end{array}$ & $\begin{array}{l}\text { Mean } R A \text { sibship } \\
\text { concordance rate } \\
\text { for siblings HLA } \\
\text { non-identical to } \\
\text { proband (\%) }\end{array}$ \\
\hline $\begin{array}{c}\text { Female } \\
(186) \\
\text { Male } \\
(45) \\
\text { Combined } \\
(231)\end{array}$ & $\begin{array}{l}16 \cdot 7(P=0 \%) \\
(n=12, n P=0) \\
9 \cdot 1(P=0 \%) \\
(n=1, n P=0) \\
15 \cdot 5(P=0 \%) \\
(n=13, n P=0)\end{array}$ & $\begin{array}{l}7 \cdot 8(P=3 \cdot 5 \%) \\
(n=16, n P=2) \\
3 \cdot 0(P=6 \cdot 1 \%) \\
(n=1, n P=3) \\
7 \cdot 1(P=3 \cdot 8 \%) \\
(n=17, n P=5)\end{array}$ & $\begin{array}{l}6 \cdot 5(P=1 \cdot 6 \%) \\
(n=4, n P=1) \\
0(P=6 \cdot 7 \%) \\
(n=0, n P=1) \\
5 \cdot 2(P=2 \cdot 6 \%) \\
(n=4, n P=2)\end{array}$ \\
\hline
\end{tabular}

$\mathrm{P}$ is the mean sibship concordance for probable disease in each category; $\mathrm{n}$ is the total number of siblings satisfying the American Rheumatism Association criteria for classical or definite disease. Two female sibships contained four and one sibship contained three
subjects with RA, including the proband. No male sibships had more than two subjects with RA including the proband. $\mathrm{nP}$ is the total subjects with RA, including the proband. No male sibships had more than two subjects with RA including the proband. $\mathrm{nP}$ is the total number of siblings satisfyin

Table 4 Comparison of mean sibship classical and definite rheumatoid arthritis $(R A)$ concordance rates in seropositive and seronegative HLA identical sibships of the same sex

\begin{tabular}{lll}
\hline $\begin{array}{l}\text { Rheumatoid factor } \\
\text { serology of } \\
\text { proband* }\end{array}$ & $\begin{array}{l}\text { Number of } \\
\text { sibships (\%) }\end{array}$ & $\begin{array}{l}\text { Mean HLA identical } \\
\text { sibship concordance } \\
\text { rate (\%) }\end{array}$ \\
\hline $\begin{array}{l}\text { Seropositive } \\
\text { (RAHA }>1 / 40)\end{array}$ & $50(70.4 \%)$ & 20.5 \\
$\begin{array}{l}\text { Seronegative } \\
\text { (RAHA } \leqslant 1 / 40)\end{array}$ & $21(29.6 \%)$ & 3.6 \\
\hline
\end{tabular}

*RAHA = rheumatoid arthritis hyaluronic acid test.

were comparable for age of proband, age of siblings, and disease duration. However, on dividing the population around the median age of the proband ( 58 years), the concordance rates for classical and definite disease were higher in the older sibships $(11 \cdot 7 v 5 \cdot 0 \%)$. This difference was not significant $\left(\chi^{2}=2.5, p>0.05\right)$.

Table 3 shows the mean sibship concordance rate for HLA identical, hemi-identical and nonidentical sibships of the same sex. The results for female sibships are higher than for the male sibships in all categories. The concordance rates in the HLA identical sibships are more than double those seen in the HLA hemi-identical and non-identical sibships. Concordant HLA identical siblings always fulfilled classical or definite RA disease criteria, whereas the HLA hemi- and non-identical siblings expressed a higher proportion of probable disease.

The HLA identical sibships were divided into seropositive (rheumatoid arthritis hyaluronic acid test $>1 / 40$ ) and seronegative (rheumatoid arthritis hyaluronic acid test $\leqslant 1 / 40$ ) disease groups and their classical and definite RA concordance rates compared (table 4). This shows that seropositive RA in the proband is associated with much higher concordance rates in HLA identical siblings of the same sex than seronegative disease.

\section{Discussion}

The concordance rates expressed in this paper are probably an overestimate of the true figures. The fact that concordant sibships are more likely to be determined if all patients with RA in the sibship attend the same hospital, and that hospital based diagnosis of patients with RA have higher concordance rates than community based diagnosis of patients with $\mathrm{RA},{ }^{8}$ will raise concordance rates. In addition, the higher concordance rates in the sibships of older probands suggest that age may have to be taken into account in a disease in which the incidence is likely to increase with time. However, all the same criticisms can also be levelled at the Arthritis and Rheumatism Council twin study, ${ }^{1}$ and this therefore allows comparisons to be made with this study.

We have not weighted for age of the proband or siblings in our calculations because we failed to show a significant difference for these variables in the multicase and non-multicase RA sibships. It is unlikely that restriction of a 50 mile radius around Newcastle significantly biased concordance rates, as RA usually begins when the patient is around 40 years old, when families have settled geographically. The likelihood of siblings having moved more than 50 miles from Newcastle is probably the same whether they develop RA or not.

Comparing the concordance rates obtained here with previous work is not easy, as many family studies did not use the American Rheumatism Association diagnostic criteria but relied on a history obtained from the proband as sole evidence of concordance or discordance, and often only quoted figures for first degree relatives without giving sibling concordance rates. ${ }^{2}$ Given these drawbacks, pooling the data from these studies gives a sibling concordance rate of $4.9 \%{ }^{8}$ The data do not allow this to be divided into female and male concordance rates. The figures in this study for women and men were 9.3 and $3.0 \%$, respectively, for classical and definite RA. Concordance rates in female sibships were therefore higher than in the male sibships. It would have been interesting to compare these results with the Arthritis and Rheumatism Council twin study for concordance rates in the female and male monozygotic and dizygotic twins, but these data are not given. Detailed results of the Arthritis and Rheumatism Council's current twin study are awaited.

Concordance rates for classical and definite RA in HLA identical sibships of the same sex are more than double those seen in hemi- and non-identical sibships. This suggests that HLA haplotypes inherited from both parents are important in the aetiology of the disease. This would be compatible with a recessive effect of HLA linked genes, but this is ruled out by the paucity of affected siblings. It would also be compatible with the alternative polygenic mode of inheritance, which appears much more likely.

Although classical and definite RA were more 
Table 5 Comparison of concordance rates (CR) for classical and definite rheumatoid arthritis related to the presence of risk factors

\begin{tabular}{lc}
\hline Risk factor & Value (\%) \\
\hline Male population prevalence $^{1}$ & $0 \cdot 7$ \\
Female population prevalence $^{1}$ & $1 \cdot 6$ \\
Male sibship CR $^{\text {Sibling CR }}$ & 3.0 \\
Dizygotic twin CR $^{1}$ & $4 \cdot 9$ \\
Female sibship CR & $5 \cdot 0$ \\
HLA identical sibship of the same sex CR & $9 \cdot 3$ \\
Seropositive HLA identical sibship of the & $15 \cdot 5$ \\
same sex CR & 20.5 \\
Seropositive monozygotic twin CR & $30 \cdot 0$ \\
\hline
\end{tabular}

likely in female and HLA identical siblings, probable RA had a higher incidence in male and HLA hemi- and non-identical siblings. This suggests the possibility that female sex and HLA identity not only predispose to the presence of RA, but also influence disease expression, making it more likely to satisfy classical or definite disease classifications. The updated American Rheumatism Association criteria for RA take a dichotomous approach to disease classification, in that a patient is classified as either having RA or not. ${ }^{10}$ For a family study such as this, this approach risks discarding potentially useful information in what is recognised to be a clinically heterogeneous disease with an evolving expression. We would advocate the continuing use of the 1958 American Rheumatism Association criteria for studies of the genetic epidemiology of RA.

If the factors of seropositivity, sex, HLA identity and hospital based determination of RA are controlled for, the resulting concordance rate for classical and definite $\mathrm{RA}$ is $\mathbf{2 0 . 5 \%}$. This is comparable with the Arthritis and Rheumatism
Council monozygotic twin concordance rate of $30.0 \%$. In other words, controlling for these factors accounts for approximately two thirds of the monozygotic twin concordance rate. Shared environmental factors are likely to be greater in twins than siblings, and may account in part for the higher concordance rate in monozygotic twins.

These data allow an ascending order of RA concordance rates corresponding to the presence of an increasing number of risk factors (table 5), and give an impression of the relative importance of these factors in predisposing to RA.

This research was funded by the Arthritis and Rheumatism Council. We thank Dr Ann Fay at the Department of Immunology, Newcastle General Hospital, for the rheumatoid factor titres.

1 Lawrence J S. Rheumatism in populations. London: Heinemann, 1977: 206-6, 231-43.

2 Deljunco D J, Luthra H S, Annegers J, Worthington W Kurland $\mathbf{L}$ 'T. The familial aggregation of rheumatoid arthritis and its relationship to the HLA-DR4 association. arthritis and its relationship to the

3 McCusker C T, Singal D P. Molecular relationship between the class II HLA antigens and susceptibility to rheumatoid arthritis. $\mathcal{F}$ Rheumatol 1988; 15: 1050-3.

4 Silman A, Ollier B, McDermott M. HLA: linkage with rheumatoid arthritis or seropositivity. $\mathcal{f}$ Rheumatol 1988 ; 15: 1189-92.

5 Ropes M W, Bennett G A, Cobb S, Jacox R, Jessar R A. Revision of diagnostic criteria for rheumatoid arthritis. Bull Rheum Dis 1958; 9: 175-6.

6 Dewar P J. HLA antigens. Clin Rheum Dis 1983; 9: 103-5.

7 Deighton C M, Walker D J. Do clinical factors predict rheumatoid arthritis concordance in same sexed sibships? Br f R heumatol 1990; 29 (suppl 1): 28.

8 Deighton C M, Walker D J, Griffiths I D, Roberts D F. The contribution of HLA to rheumatoid arthritis. Clin Genet 1989; 36: 178-82.

9 Silman A J, Ollier W, Hayton R M, Holligan S, Smith I L. Twin concordance rates for rheumatoid arthritis: preliminary results from a nationwide study. $\mathrm{Br} \mathcal{F}$ Rheumatol 1990 ; 28 (suppl 2): 95.

10 Arnett F C, Edworthy S M, Bloch D A, et al. The American Rheumatism Association criteria for the classification of rheumatoid arthritis. Arthritis Rheum 1988; 31: 315-23. 